\title{
The Effectiveness of Mindfulness Training on Self- regulation and Perceived Academic Control of Girl Students
}

DOI: https://doi.org/10.47175/rissj.v2i2.223

\section{| Fatemeh Darabi | \\ Master of Educational Psychology, Faculty of Psychology and Education, Allameh Tabataba'i University, Iran.}

fatemeh.darabi74@yahoo.com

\begin{abstract}
The aim of this study was to determine the effectiveness of mindfulness training on self-regulation and perceived academic control of female students. The research is applied in terms of purpose and quasi-experimental in terms of method using pretest-posttest with a control group. The statistical population of this study consisted of all female high school students in Tehran in the academic year 2019-2020. First, a school was selected from among them and 30 students were selected by random sampling method and were randomly assigned to the experimental group (15 people) and the control group (15 people). The experimental group was trained in 8 sessions of the Mindfulness Training Program (2017). The self-regulatory questionnaire by Pintrich and DeGroot (1990) and the Perry et al.'s (2001) Conscious Academic Control Scale were used to collect data. One-way covariance test was used to analyze the data. The results showed that mindfulness training method has a significant effect on increasing students' self-regulation and conscious academic control. KEYWORDS

self-regulation; mindfulness; perceived academic control
\end{abstract}

\section{INTRODUCTION}

One of the important goals of education is to create the conditions for the all-round development of the individual and to train healthy, efficient and responsible people to play a role in individual and social life. Since students; as the basic pillar of the country's educational system, they have a special role and position in achieving the goals of the educational system. However, of all the students who enter the education system, only a few can develop their talents and succeed in this field and show good academic performance. One of the most important and influential factors in students' academic factors is their psychological factors (Mikaeli, Gholamali and Gholizadeh, 2012). One of the important psychological characteristics that affect academic performance is academic self-regulation and perceived academic control. Self-regulation is the capacity of the individual to adjust behaviors according to the conditions and changes of the internal and external environment. Of course, self-regulation should not be equated with judging processes for changing environmental conditions. Self-regulation involves an individual's capacity to organize and behave according to goals (Limous, 1999). In the field of education, self-discipline can be defined as spontaneous thoughts, feelings, and activities in order to achieve educational goals (Zimmerman, 1998). Self-regulation is a valuable concept in modern education and an important research and experimental approach in educational, cognitive and clinical psychology. A review of research and theories reveals that self-regulatory learning is an important part of the learning literature, and that cognitive and emotional self-regulation is an important aspect of students' learning and 
academic performance in the classroom (Pantrich, 2004; Desi and Ryan, 2008) Regarding the importance of paying attention to self-regulation, it should be said that theories of selfregulation learning theory have a great potential in conducting research that focuses on students' study patterns. They also help students become more self-sufficient and effective learners. Also, self-regulatory learning has created a new and important approach to studying students' academic success. Prior to this, the student's success was measured in terms of measuring his or her abilities or the quality of teaching and schools and the home environment; conversely, the theory of self-regulation emphasizes how students engage in personal activity and how they refine their learning methods in a particular context (Zimmerman, 1986).

Another influential variable in students 'academic outcomes that increases students' cognitive actions and commitment to graduation and completion of the course is conscious academic control (Ruthig et al., 2009), which facilitates the effects of optimism on psychological health. Protects students from their declining mental health (Ruthig, 2009). Perceived academic control refers to a belief in a person's abilities that affects or controls his or her academic results. Perceived academic control, as it relates to human beliefs, can play a role in people's cognitive evaluation of events. It seems that due to the role of cognitive beliefs and related distortions in evaluating educational events as stressful and anxious events, the creation, elimination, strengthening or weakening of these distortions can be consciously controlled under academic control. Based on this, it can be stated that the type and intensity of emotions and feelings of the individual about different educational events can also be predicted according to the degree of conscious academic control. In such situations, perceived academic control can facilitate the effects of optimism on promoting mental health and protect students from psychological distress. Considering the importance of informed academic control to increase students' autonomy and responsibility and the great impact it has on students' academic growth and success, and the ability to increase students' perceived academic control shown in repeated empirical research, it is important (Perry, Hladkyj, Pekrun, Pelletier, 2001: Ruthig et al., 2009) showed that relative academic optimism predicts perceived academic control, and that students may increase conscious academic control through optimistic social comparison. Research has shown that students who are optimistic have higher academic control than their non-optimistic counterparts, and academic optimism is associated with a strong sense of control that predicts further progress and consequently greater psychological adjustment. Bandura (1994) also believes that people who believe that they can control their actions do not find disruptive thought patterns threatening, and those who believe that they cannot manage threats experience high levels of anxiety as well as many aspects of their environment full of danger. They see and magnify potential threats and worry about things that rarely happen. As a result, self-efficacy beliefs include the degree to which individuals believe they can control their levels of performance and their environment (Bandura, Barbaranelli, Caprara, and Pastorelli, 1996). Thus, the three psychological theories of motivation, selfefficacy, and attribution agree to explain the source paradigm of academic control. Negative emotion and poor academic performance are commonly associated with academic failure in students with little or no sense of academic control (Lavender et al., 2010; Gypsy, Collie, Martin, Malmberg, Hall \& Ginns, 2015).

Among the approaches and therapies that therapists have used for self-regulation, we can mention the effectiveness of cognitive-behavioral training (Hakimzadeh, Lavasani and Norouzi, 2014) and problem solving skills (Miri, 2012). Among the trainings used for the source of control, we can name the group of cognitive-behavioral therapy based on Ellis's 
logical-emotional approach (Hamidi, Eidi Baigi, Atai Moghanloo and Motalebi, 2013). One of the methods that seems to be effective on self-discipline and perceived academic control is mindfulness training. Mindfulness is generally referred to as cognitive processes in which the mindful person focuses on experiences, feelings, and events that it occurs in the moment, in or around itself (Bauer, Smith, \& Allen, 2004). In other words, mindfulness involves adopting a non-judgmental attitude towards personal experiences that are ongoing at the moment. It therefore allows the individual to react less and be more receptive to these experiences (Shapiro, Carlson, Stein, \& Friedman, 2006). In fact, the term mindfulness can be defined as a psychological attribute, thought exercise, or a particular state of consciousness (Caldwell and Shaver, 2013). On the other hand, mindfulness is a receptive and non-judgmental consciousness of current events that is created according to the goal in the current moment without inference from moment to moment. Mindfulness is the observation of internal and external stimuli as they occur without any judgment or prejudice. Mindfulness is a skill that allows people to take events for less than what is distressing, and allows people to perceive internal and external realities freely and without distortion, and has a great ability to cope with a wide range of thoughts, emotions. And find experiences, both pleasant and unpleasant. Mindfulness has a positive relationship with peace of mind and psychological health and can be considered as self-regulating attention and directing it towards task (Kabat-Zinn, 2005).

However, according to studies, no attempt has been made to make this approach effective on perceived self-regulation and academic control. Therefore, ignoring the mindfulness approach in increasing self-discipline and perceived academic control can be considered as a serious gap in the literature on intervention in perceived self-regulation and academic control, which the purpose of this study is to fill part of it. Therefore, the present study sought to answer the question of whether mindfulness training can significantly affect the level of self-regulation and perceived academic control of students or not?

\section{RESEARCH METHODS}

This research is applied in terms of purpose and semi-experimental in terms of research method using pretest-posttest with a control group. The independent variable was mindfulness-based cognitive therapy that was applied only in the experimental group and its effect on the post-test scores of the experimental group was compared with the control group. The statistical population of the present study was all female high school students in the city of Tehran in 2009-2010. To select the sample, according to the limitations in sampling, first one school was selected from among the high schools in Tehran and then 30 students were selected by simple random sampling method and randomly in the experimental group (15 patients) and the control group (15 patients) were replaced. The criterion for entering the research was conscious consent to participate in the research and the criterion for leaving the research was dissatisfaction with continuing to participate in the research process. At first, the participants of the experimental group and the control group were asked to fill in the self-regulation and academic control questionnaire, then the participants of the experimental group received 8 sessions of mindfulness training program (2 months, once a week and approximately every day, One and a half hour) and the control group participants did not receive any program and continued their normal routine. Group sessions were conducted by the researcher on the experimental group. Each session was with the participation of members and workshop activities. After the training sessions, the participants of the experimental group and the control group again filled out the selfregulatory questionnaire and perceived academic control. 


\section{Research Instruments}

Self-Regulation Questionnaire (MSLQ): The Self-Regulation Strategies Questionnaire (MSLQ) was developed by Pintrich and DeGroot in 1990. This questionnaire is organized with 47 phrases in two sections of motivational beliefs and self-regulatory learning strategies (cognitive and metacognitive strategies). The subscale of self-directed learning strategies consists of 22 terms and measures three aspects of academic self-regulation: cognitive strategies, metacognitive strategies, and motivational beliefs. Cognitive strategies, 13 phrases are as follows: Repetition and review including phrases 44, 37, 29; Expansion including note-taking including phrase 34; Summary including phrases 45, 31; Organization includes phrases 47, 42, 39, 27, 26 and comprehension includes phrases 33, 32. Metacognitive Strategies and Resource Management. Monitoring and control including phrases 43, 41, 35, 28; Regulating includes the effort and perseverance of phrases 36, 30 and the activity of regulating phrase 40 . The section on motivational beliefs includes 25 phrases: self-efficacy including 22,21,19,14,12,10,9,6,6; Orientation of the purpose of the expressions $24,16,11,4,1$; Internal evaluation of the expressions $20,17,8,5$ and test anxiety of the expressions 25,23,18,15,13,7,3.

Perceived Academic Control Scale: The Conscious Academic Control Scale developed by Perry et al. (2001) was used to assess perceived academic control. This scale includes two subscales of academic responsibility and academic controllability and has eight questions, four positive sentences and four negative sentences with scores from strongly agree to strongly disagree, which includes a score of (1-5). Items 2, 4, 5, 7, 8 are related to the responsibility component and items $1,6,3$ are related to the controllability components. In this scale, the answers are summed up with negative sentences 3,5,6,8 and the highest scores indicate higher academic control. The data of the Likert scale questionnaire are graded. The possible score will be 8 and a maximum of 40 . Perry et al. (2001) reported its reliability in their study by Cronbach's alpha of 0.80 and in Hosseini and Khair (2011), the reliability of this questionnaire through Cronbach's alpha was reported to be 0.70 . Is. Also, the results of confirmatory factor analysis of the questionnaire in Hosseini and Khair (2011) study indicated the acceptable validity of the questionnaire and confirmed the results of subscales. In this study, the reliability of the instrument was measured by Cronbach's alpha test and the result of responsibility of 0.83 and controllability of 0.81 was reported, which is confirmed.

Mindfulness Therapy Package: A brief description of mindfulness training sessions (Table 1) taken from the Handbook of Cognitive Therapy Based on Mindfulness (Rebecca Crane, 2017).

Table 1. Objectives and content of training sessions

\begin{tabular}{cll}
\hline Session & \multicolumn{1}{c}{ Objectives } & \multicolumn{1}{c}{ Content } \\
\hline 1 & $\begin{array}{l}\text { Create automatic } \\
\text { navigation }\end{array}$ & $\begin{array}{l}\text { Setting a general policy taking into account the confidentiality } \\
\text { of individuals' personal lives, inviting people to introduce } \\
\text { themselves to each other, and forming a group }\end{array}$ \\
\hline 2 & $\begin{array}{l}\text { Familiarity with how } \\
\text { to deal with obstacles }\end{array}$ & $\begin{array}{l}\text { Physical vigilance, ten minutes of mindfulness on the flow of } \\
\text { breathing }\end{array}$ \\
\hline 3 & $\begin{array}{l}\text { Perform conscious } \\
\text { breathing }\end{array}$ & $\begin{array}{l}\text { Movement with the presence of the mind, doing stretching and } \\
\text { breathing with the presence of the mind, followed by } \\
\text { meditation in a sitting position focused on awareness of } \\
\text { breathing and body }\end{array}$ \\
\hline 4 & $\begin{array}{l}\text { Practicing in the } \\
\text { present }\end{array}$ & $\begin{array}{l}\text { Awareness of breathing, body, sounds, thoughts and } \\
\text { awareness without special orientation, three-minute breathing }\end{array}$ \\
\hline
\end{tabular}




\begin{tabular}{cll}
\hline 5 & $\begin{array}{l}\text { Create acceptance } \\
\text { and permission }\end{array}$ & $\begin{array}{l}\text { space: Introducing this method as a coping strategy for use in } \\
\text { times when the situation evokes difficult emotions }\end{array}$ \\
\hline 6 & $\begin{array}{l}\text { Meditation while sitting, awareness of breathing and body, } \\
\text { emphasis on understanding how the thoughts, feelings and } \\
\text { sensations of the body react }\end{array}$ \\
\hline 7 & Learn self-care & $\begin{array}{l}\text { Attention training technique: meditation in a sitting position, } \\
\text { awareness of breathing and body, in addition to introducing } \\
\text { the problem related to exercise and realizing its effects on the } \\
\text { body and mind, pleasant and unpleasant thoughts }\end{array}$ \\
\hline 8 & $\begin{array}{l}\text { Apply what you have } \\
\text { thoughts and emotions, understanding the relationship } \\
\text { between activity and mood }\end{array}$ \\
\hline & $\begin{array}{l}\text { Use what you have learned to cope with mood swings in the } \\
\text { future }\end{array}$ \\
\hline
\end{tabular}

\section{RESULTS AND DISCUSSION}

In order to better understand the nature of the population under study and become more familiar with the research variables, it is necessary to describe these data before analyzing the statistical data. In terms of demographic characteristics, all participants were female and ranged in age from 15 to 17 years. Table 2 also describes the descriptive characteristics of the whole sample, including scattering indices (standard deviation) and centrifugal indices (mean). In the self-regulation questionnaire, the minimum and maximum scores were 47 and 225, respectively, and in the academic control questionnaire, the minimum and maximum scores were 7 and 35 , respectively.

Table 2. Mean and standard deviation of self-regulated scores in pre-test and post-test

\begin{tabular}{|c|c|c|c|c|c|}
\hline & Post-test & & Pre-test & & \\
\hline $\begin{array}{l}\text { Standard } \\
\text { deviation }\end{array}$ & Average & $\begin{array}{l}\text { Standard } \\
\text { deviation }\end{array}$ & Average & Group & Variables \\
\hline 17.3 & 179.5 & 20.2 & 178.8 & experimental & Cognitive strategies \\
\hline 38.5 & 136.5 & 39.3 & 133.7 & control & \\
\hline 21.1 & 162.2 & 16.7 & 153.8 & experimental & Metacognitive strategies and \\
\hline 19.8 & 145.5 & 21.1 & 145.8 & control & resource management \\
\hline 15.08 & 170.7 & 20.3 & 161.5 & experimental & Motivational beliefs \\
\hline 25.5 & 143.8 & 37.3 & 140.1 & control & \\
\hline
\end{tabular}

As can be seen in Table 2, there is no significant change in the pre-test and post-test of the control group, but in the experimental group the mean of the post-test is higher than the pre-test.

Table 3. Mean and standard deviation of conscious academic control scores in pre-test and post-test

\begin{tabular}{|c|c|c|c|c|c|}
\hline & Post-test & & Pre-test & & \\
\hline $\begin{array}{l}\text { Standard } \\
\text { deviation }\end{array}$ & Average & $\begin{array}{l}\text { Standard } \\
\text { deviation }\end{array}$ & Average & Group & Variables \\
\hline 4.81 & 28.6 & 3.23 & 24.1 & experimental & Responsibility \\
\hline 4.35 & 24.3 & 4.69 & 23.9 & control & \\
\hline 3.99 & 25.5 & 3.98 & 18.8 & experimental & Controllability \\
\hline 5.43 & 20.6 & 4.40 & 18.9 & control & \\
\hline
\end{tabular}

Table 3 shows the standard deviation and the mean of conscious academic control of the experimental and control groups in the pre-test and post-test. According to Table 3, the 
academic control of the experimental group in the post-test part has a significant increase compared to the pre-test, which is not seen in the control group.

\section{Inferential Findings}

Investigating the homogeneity of variances

After describing the statistical data, the results of the statistical test are reported in this section. In this study, analysis of covariance test was used to analyze the data. To use covariance, its presuppositions, i.e. homogeneity of variances, must be tested by Levin test. These assumptions are examined below.

Table 4. Levin test to check the homogeneity of variances

\begin{tabular}{rrrrr}
\hline Significance & Df2 & Df1 & F & Variable \\
\hline 0.148 & 28 & 1 & 2.209 & Cognitive strategies \\
\hline 0.608 & 28 & 1 & 0.268 & $\begin{array}{r}\text { Metacognitive strategies and } \\
\text { resource management }\end{array}$ \\
\hline 0.273 & 28 & 1 & 1.252 & Motivational beliefs \\
\hline 0.788 & 28 & 1 & 0.079 & Responsibility \\
\hline 0.789 & 28 & 1 & 0.073 & Controllability \\
\hline
\end{tabular}

Levin test was used to examine the default equality of variances in groups $(p<0.05)$ (Table 4). The results of Levin test show that homogeneity of variances is observed.

\section{Normality of data}

When checking the normality of the data, the null hypothesis that the data distribution is normal is checked at the 5\% error level. Therefore, if the test statistic is greater than or equal to $5 \%$, then there is no reason to reject the null hypothesis that the data distribution is normal. To test the normality of data distribution, statistical hypotheses are set as follows:

- Null Hypothesis: The distribution of data related to each of the variables is normal.

- Alternative Hypothesis: The distribution of data related to each of the variables is not normal.

Table 5. Results of Kolmogorov-Smirnov test to check the normality of variables

\begin{tabular}{rrr}
\hline Kolmogorov-Smirnov test & $\mathbf{Z}$ \\
\hline 0.64 & 0.74 & Variables \\
\hline 0.50 & 0.83 & $\begin{array}{r}\text { Metacognitive strategies and } \\
\text { resource management }\end{array}$ \\
\hline 0.52 & 0.81 & Motivational beliefs \\
\hline 0.27 & 0.99 & Conscious academic control \\
\hline 0.42 & 0.88 & Conscious responsibility \\
\hline
\end{tabular}

As shown in Table 5, all research variables have a normal distribution $(\mathrm{p}<0.05)$. In other words, the null hypothesis for the normal distribution of scores of self-regulatory and academic control variables as well as subscales of both variables in both control and experimental groups has been confirmed. Therefore, the assumption that the distribution of scores of variables is normal in both control and experimental groups is confirmed. 


\section{Mindfulness training affects the cognitive strategies of female students.}

Table 6. Results of analysis of covariance the effectiveness of mindfulness training on cognitive strategies

\begin{tabular}{rrrrrrrrr}
\hline $\begin{array}{r}\text { Statistical } \\
\text { power }\end{array}$ & $\begin{array}{r}\text { Squared } \\
\text { Eta }\end{array}$ & $\begin{array}{r}\text { Significance } \\
\text { Level }\end{array}$ & F & $\begin{array}{r}\text { Average of Degrees of } \\
\text { Squares }\end{array}$ & $\begin{array}{r}\text { Sum of } \\
\text { Freedom }\end{array}$ & Group & Variable \\
\hline 0.22 & 0.051 & 0.230 & 1.505 & 1223.685 & 1 & 1223.685 & Pre-test & \\
\hline 0.987 & 0.387 & 0.000 & 17.017 & 15723.141 & 1 & 15723.141 & $\begin{array}{r}\text { Effect } \\
\text { therapy }\end{array}$ & $\begin{array}{r}\text { Cognitive } \\
\text { strategies }\end{array}$ \\
\hline & & & & & & & & \\
\hline
\end{tabular}

Because the researcher is trying to eliminate possible initial differences between groups, covariance analysis should be used. There was a significant increase in self-regulation of the experimental group in the post-test compared to before the intervention $(\mathrm{p}<0.05)$ (Table 6). It can be said that mindfulness training on cognitive strategies has been desirable. Mindfulness training has been able to significantly increase cognitive strategies. Eta squared, which indicates the effect of the intervention, states that the intervention was able to differentiate $37.8 \%$ of the variances within the experimental group. Therefore, the hypothesis is confirmed.

\section{Mindfulness training has an effect on the discipline and control strategies (metacognitive and resource management) of female students.}

Table 7. Results of analysis of covariance the effectiveness of mindfulness training on metacognitive strategies

\begin{tabular}{rrrrrrrrr}
\hline $\begin{array}{r}\text { Statistical } \\
\text { Power }\end{array}$ & $\begin{array}{r}\text { Squared } \\
\text { Eta }\end{array}$ & $\begin{array}{c}\text { Signific- } \\
\text { ance Level }\end{array}$ & F & $\begin{array}{c}\text { Average of Degrees of } \\
\text { Squares }\end{array}$ & $\begin{array}{r}\text { Sum of } \\
\text { Freedom }\end{array}$ & Group & Variable \\
\hline 0.051 & 0.000 & 0.931 & 0.008 & 3.647 & 1 & 3.647 & Pre-test & \\
\hline 0.535 & .0139 & 0.043 & 4.503 & 2008.026 & 1 & 2008.26 & $\begin{array}{r}\text { Effect } \\
\text { therapy }\end{array}$ & $\begin{array}{r}\text { Cognitive } \\
\text { Strategies } \\
\text { and resource } \\
\text { management }\end{array}$ \\
\hline & & & & & & & & \\
\end{tabular}

Based on the results of Table 7, it can be seen that after adjusting the pre-test scores, there was a significant effect of group factor $(\mathrm{P}<0.05)$ and $(\mathrm{F}=4.503)$. The adjusted mean scores show that people who received mindfulness training had much higher selfregulation and control strategies (metacognitive and resource management) than the control group. According to ETA square, the effect of this intervention in the post-test was $13.9 \%$.

\section{Mindfulness training affects the motivational beliefs of female students.}

Table 8. Results of analysis of covariance the effectiveness of mindfulness training on motivational beliefs

\begin{tabular}{|c|c|c|c|c|c|c|c|c|}
\hline $\begin{array}{r}\text { Statistical } \\
\text { Power }\end{array}$ & $\begin{array}{r}\text { Squared } \\
\text { Eta }\end{array}$ & $\begin{array}{l}\text { Signific- } \\
\text { ance Level }\end{array}$ & $\mathrm{F}$ & $\begin{array}{c}\text { Average of } \\
\text { Squares }\end{array}$ & $\begin{array}{l}\text { Degrees of } \\
\text { Freedom }\end{array}$ & $\begin{array}{r}\text { Sum of } \\
\text { Squares }\end{array}$ & Group & Variable \\
\hline 0.092 & 0.14 & 0.540 & 0.385 & 305.921 & 1 & 305.621 & Pre-test & \\
\hline 0.810 & 0.236 & 0.006 & 8.648 & 7019.640 & 1 & 7019.640 & $\begin{array}{r}\text { Effect } \\
\text { therapy }\end{array}$ & $\begin{array}{r}\text { Motivational } \\
\text { beliefs }\end{array}$ \\
\hline & & & & 77.84 & 28 & 2224.29 & error & \\
\hline
\end{tabular}


Based on the results of Table 8 , it can be seen that after adjusting the pre-test scores, there was a significant effect of group factor $(\mathrm{P}<0.05)$ and $(\mathrm{F}=8.648)$. The adjusted mean scores show that people who received mindfulness training had much higher motivational beliefs than the control group. According to ETA square, the effect of this intervention in the post-test was $23.6 \%$.

\section{Mindfulness training has an effect on academic control of female students.}

Table 9. Results of analysis of covariance the effectiveness of mindfulness training on conscious academic control

\begin{tabular}{rrrrrrrrr}
\hline $\begin{array}{r}\text { Statistical } \\
\text { Power }\end{array}$ & $\begin{array}{r}\text { Squared } \\
\text { Eta }\end{array}$ & $\begin{array}{r}\text { Signific- } \\
\text { ance Level }\end{array}$ & F & $\begin{array}{c}\text { Average of Degrees of } \\
\text { Squares }\end{array}$ & $\begin{array}{r}\text { Sum of } \\
\text { Freedom }\end{array}$ & Group & Variable \\
\hline 0.051 & 0.000 & 0.914 & 0.012 & 0.208 & 1 & 0.208 & Pre-test & \\
\hline 0.197 & 0.044 & 0.033 & 1.304 & 26.133 & 1 & 26.133 & $\begin{array}{r}\text { Effect } \\
\text { therapy }\end{array}$ & Controllability \\
\hline & & & & & 0.409 & 28 & 11.71 & error \\
\hline
\end{tabular}

Based on the results of Table 9, it can be seen that after adjusting the pre-test scores, there was a significant effect of group factor $(\mathrm{P}<0.05)$ and $(\mathrm{F}=1.304)$. The adjusted mean scores show that people who received mindfulness training had higher informed academic control compared to the control group. As a result, the hypothesis that mindfulness training has an effect on the conscious academic controllability of female students is confirmed.

\section{Mindfulness training affects the academic responsibility of female students.}

Table 10. Results of analysis of covariance the effectiveness of mindfulness training on conscious academic responsibility

\begin{tabular}{rrrrrrrrr}
\hline $\begin{array}{r}\text { Statistical } \\
\text { Power }\end{array}$ & $\begin{array}{r}\text { Squared } \\
\text { Eta }\end{array}$ & $\begin{array}{r}\text { Signific- } \\
\text { ance Level }\end{array}$ & F & $\begin{array}{c}\text { Average of Degrees of } \\
\text { Squares }\end{array}$ & $\begin{array}{r}\text { Sum of } \\
\text { Freedom }\end{array}$ & Group & Variable \\
\hline 0.052 & 0.001 & 0.900 & 0.016 & 0.261 & 1 & 0.261 & Pre-test & \\
\hline 1.00 & 0.100 & 0.042 & 1.114 & 18.883 & 1 & 18.883 & $\begin{array}{r}\text { Effect } \\
\text { therapy }\end{array}$ & Responsibility \\
& & & & & 0.549 & 28 & 16.625 & error \\
\hline
\end{tabular}

Based on the results of Table 10, it can be seen that after adjusting the pre-test scores, there was a significant effect of group factor $(\mathrm{P}<0.05)$ and $(\mathrm{F}=1.114)$. The adjusted mean scores show that people who received mindfulness training had higher conscious academic responsibility compared to the control group. According to Eta squared, the effect of this intervention in the post-test was $10 \%$.

\section{CONCLUSION}

The main purpose of this study is the effectiveness of mindfulness training on selfregulation and perceived academic control of female students. The results show that mindfulness training on cognitive strategies, metacognitive strategies, motivational beliefs, academic controllability and academic responsibility of female students' relationship there is a positive and significant and in general it can be acknowledged that mindfulness training has an effect on self-regulation and perceived academic control of female students. The results showed that the relationship between mindfulness training and self-regulation of female students is positive and significant. Based on Arouti, Ebrahimi, Saadipour, Delavar and Dortaj (2019), it can be concluded that the reproductive education program is effective in increasing cognitive, metacognitive self-regulation and motivational beliefs of students. The results of Malek Mohammadi and Ghorbani Bosari (2019) showed the effect 
of mindfulness training on self-regulation in students with depression. The results of Engelschalk, Store and Drissel (2016) study entitled self-regulatory education in students 'academic achievement motivation showed that self-regulatory education has a positive and significant effect on students' academic achievement motivation. The results of $\mathrm{Yu}$ and Kong (2014) showed that pleasure has a moderating role between perceived academic control and self-regulation, but fatigue and anxiety showed a moderating effect on the relationship between perceived academic control and self-regulation. The results indicate that the relationship between mindfulness training and perceived academic control of female students is positive and significant. Accordingly, in line with the results of research by Haddad Ranjbar and Chegini (1397) showed that positive emotions not only have a positive and direct effect on metacognitive self-regulation but can also facilitate the effect of perceived academic control on metacognitive self-regulation. Findings of Baranian, Zoghibi Qannad (1397) showed that people with high self-efficacy have more academic control and are less likely to engage in academic dishonesty. The results of Mori, Pour, Akbari Borang (1397) indicate that there is a positive and significant relationship between self-discipline and scientific-perceptual control over students' academic achievement. Fardafshari, Pourshahriyar, Shokri and Fathabadi (2017) Based on the obtained results, the indirect effect of tendency optimism on psychological disturbance through conscious academic control (academic responsibility and academic controllability) is predictable. Ghanbari and Masoudi (2016) with the title of mindfulness based on cognitive pattern on early maladaptive schemas, the source of control and cognitive regulation of emotion, showed that training cognitive skills based on cognitive pattern on early maladaptive schemas, The source of control and cognitive regulation of students' emotion has been effective. The results of Khalili Ezzatabadi Zadeh (2016) indicate that the higher the students' academic control and the more appropriate self-regulation strategies, the higher their psychological well-being. In a study comparing self-esteem and perceived academic control as predictors of students, Stopinsky and Perry (2013) concluded that emotion, impatience, and anxiety are positive predictors of perceived academic control. In contrast, students' self-esteem is negatively related to anxiety. The results of Solberg and Segstrom (2010) showed that students who have a strong sense of control have more autonomy, supervisory strategies, responsibility and a sense of control over homework and also use more learning guidance. The results of these studies are inconsistent with Rezapour Mir Saleh and Fotouhi Ardakani (2016) in their research concluded that only in terms of student perception of learning between gifted and control students (in favor of control schools) there was a significant difference and in While the other dimensions of the educational-learning environment as well as the source of academic control, there was no difference between the two schools.

Explaining the hypothesis of mindfulness training on self-regulation can be stated: Selfregulation is an important aspect of students' learning and academic performance in the classroom environment. Thus, self-discipline determines what the student is studying for and what they need to know about themselves and their academic work in order to learn independently. Perceived academic control, on the other hand, refers to an individual's belief in his or her "perception" of abilities that reflect that person's mentality and not necessarily objective features (Thompson-Sobel-Shobin, Galbraith, Schwankovsky, \& Kruzen, 1993). Practicing frequent focus on neutral phenomena such as breathing, awareness of thoughts and physical feelings increases self-control. Because this insight and awareness creates a sense of responsibility to manage thoughts, emotions in people, and to the extent that people can manage the type and intensity of their emotions and feelings 
about different educational events, they will have better and higher adaptation to environmental conditions. Students who manage negative emotions better thus feel better and more in control of homework and the whole of life. Therefore, as the mindfulness of individual increases, along with it, the adaptive performance of the individual, skills such as understanding, comprehending, managing and controlling the emotions of oneself and others, as well as the quality of academic life of individuals, increase. There were some limitations in the present study: The present study was conducted using a quasiexperimental design. It is worth mentioning that the use of experimental design requires careful control of variables and other factors, so it is natural that in such research, there are problems and obstacles that are beyond the control of the researcher in practice, as well as the short time between pre-test and post-test. It can be mentioned as a factor in the limitation of research, because it makes the risk of pre-test effect in the research process possible. For further research, it is suggested that due to the quantitative nature of this project, in another study with the same title, researchers to qualitatively examine the relationship between variables and the effect of mindfulness training on students' selfregulation and academic control in the form of case and field study. The statistical population of the present study was limited to female high school students. Due to the ethnic, biological, racial and cultural diversity that prevails in the country, it is suggested that other educational levels and age groups in other statistical communities be examined and analyzed, and also that counselors and psychologists are recommended to use the method Use mindfulness training to improve students' self-discipline and conscious academic control skills.

\section{REFERENCES}

Akbari, Maryam. Arjmandnia, Ali Akbar. Afrooz, Gholam Ali and Kamkar, Kambiz (2015). The effectiveness of mindfulness training on self-regulation and academic achievement of students with learning disabilities. Journal of Behavioral Science Research, 15 (4), 8-16.

Baranian, Sahar and Zaghibi Qanad, Simin. (1397). Investigating the relationship between educational environment and academic self-efficacy with academic dishonesty mediated by academic control and the moderating role of self-esteem in students. Sixth National Conference on Modern Studies and Research in the Field of Educational Sciences, Psychology and Counseling in Iran.

Taj al-Dini, Saida; Touhidi, Afsaneh; Mousavi Nasab, Seyed Hossein. (1397). The effect of mindfulness-based stress reduction education on academic vitality, academic selfregulation, and mindset of high school students. Journal of Educational Psychology Studies, 31.

Jeweler Zadeh, Mahrokh. Soltani Kuhbanani, Sakineh. (1395). The effectiveness of mindfulness skills training on motivational structure of female students. Journal of Mental Health Principles. 75, 440-436.

Hamedi, Maryam; Mirzaeian, Bahram; Hassanzadeh; Ramadan (1395). The effectiveness of mindfulness-based cognitive therapy on anxiety and positive metacognitive beliefs about worry in students with test anxiety, Journal of New Psychological Ideas, (1) 21, 11-20.

Haddad Ranjbar, Somayeh and Chegini, Maryam. (1397). The Relationship between Perceived Academic Control and Learning Metacognitive Self-Regulation: The Mediating Role of Positive Academic Emotions. Fifth National Conference on School Psychology. 
Khalili Ezzatabadi Zadeh, Masoumeh. (2015). The relationship between perceived academic control, self-regulation in learning and psychological well-being of high school students. Master Thesis, Islamic Azad University, Pomegranate Branch.

Rezapour Mir Saleh, Yaser and Fotouhi Ardakani, Ezzat. (2015). Comparison of educational-learning environment and source of academic control in students of talented students schools, government and control sample. Journal of Educational Research, 32, 20-38.

Seif, Ali Akbar. (1396). Modern parenting psychology, learning and teaching psychology. Tehran: Doran Publications.

Abedi, Fatemeh; Khademi Ashkazari, Muluk (1396). The effect of mindfulness-based cognitive education on the dimensions of students' psychological well-being. Journal of Psychological Studies, 51, 111-128.

Fard Afshari, Sara, Poor Shahriar Hossein, Shokri, Omid; Fathabadi, Jalil. (1396). The Relationship between Optimism and Psychological Disorder in Students: The Mediating Role of Conscious Academic Control. Journal of Education and Learning Studies (Social Sciences and Humanities, Shiraz University), 9 (2), 1-19.

Ghorbannejad, Ali. Mohammadipour, Mohammad and Soleimanian, Ali Akbar. (1397). The effectiveness of mindfulness training method on intelligence beliefs and study strategies in male students. Sociology of Education. 6, 31-16.

Ghanbari Talab, Mohammad. (1395). The relationship between mindfulness and academic self-efficacy. Master Thesis, Faculty of Psychology and Educational Sciences, Payame Noor University, Tabriz Branch.

Ghanbari Talab, Mohammad Javanmard, Gholam Hossein and Rezaei, Akbar (1398). Investigating the relationship between mindfulness, attention and academic selfefficacy. Journal of Psychological Development, 8 (5), 194-204.

Malek Mohammadi, song; Victim of Bosari, Shahla. (1398). the Effectiveness of Mindfulness on Self-Regulation of Students with Depression, Fifth National Conference on Recent Innovations in Psychology, Applications and Empowerment Focusing on Psychotherapy

Mehrabi, Ismail Moradian, Mitra and Amani, Shirin (1397). Evaluation of the effectiveness of mindfulness training on increasing self-regulation of eighth grade high school students. 4th International Conference on New Horizons in Educational Sciences, Psychology and Social Injury.

Vahedi, Shahram; Fathi Azar, Alexander; Adib, Yusuf and Qara Aghaji, Saeed. (1397). The effectiveness of education program based on self-regulation, mindfulness and time management on reducing procrastination and increasing academic achievement of high school students. Journal of Educational Psychology Studies, 30, 275-241.

Hashemi, Seyed Ismail and Mahour, Hossein. (2015). The effectiveness of mindfulness training on students' happiness. Journal of Clinical Psychology and Counseling Research, 6 (2), 111-120.

Arsal, Z. (2010). The Effects of Diaries on Self-Regulation Strategies of Preservice Science Teachers. International Journal of Environmental and Science Education, 5 (1), 85-103.

Baer, R. A., Smith, G. T., \& Allen, K. B. (2004). Assessment of mindfulness by selfreport: The Kentucky Inventory of Mindfulness Skills. Assessment, 11 (3), 191-206.

Bandura, A. (1994). Self-efficacy: Encyclopedia of Human behavior (Vol. 4, pp. 71-81): New York: Academic Press. 
Collie, R. J. , Martin, A. J. , Malmberg, L. E. , Hall, J. , \& Ginns, P. (2015). Academic buoyancy, student's achievement, and the linking role of control: A cross lagged analysis of high school students. British Journal of Educational Psychology, 85 (1), 113-130.

Connor, C. M., Ponitz, C. C., Phillips, B. M., Travis, Q. M., Gladney, S., \& Morrison, F. J. (2010). First graders' literacy and self-regulation gains: The effect of individualizing student instruction. Journal of School Psychology, 48(5), 433-455.

Deci, E. L., \& Ryan, R. M. (2008). Self-determination theory: A macro theory of human motivation, development, and health. Canadian Psychology/Psychology Canadians, 49(3), 182.

Engelschalk, T., Steuer, G., \& Dresel, M. (2016). Effectiveness of motivational regulation: Dependence on specific motivational problems. Learning and Individual Differences, 52(1), 72-78.

Hall, N. C. , Chipperfield, J. G. , Perry, R. P. , Ruthig, J. C. , \& Goetz, T. (2006). Primary and secondary control in academic development: Gender-specific implications for stress and health in college students. Anxiety, stress, and coping, 19(2), 189-210.

Lemos, M. S. (1999). Students' goals and self-regulation in the classroom. International journal of educational research, 31(6), 471-485.

MacKenzie, M. J., \& Baumeister, R. F. (2015). Self-regulatory strength and mindfulness. In B. D. Ostafin, M. D. Robinson, \& B. P. Meier (Eds.), Handbook of mindfulness and self-regulation (pp. 95-105). New York: Springer.

McCloskey, L. E. (2014). Mindfulness as an intervention for improving academic success among students with executive functioning disorders. Procedia-Social and Behavioral Sciences, 174, 221-226.

Pekrun R. (2006). The control-value theory of achievement emotions: assumptions, corollaries, and implications for educational research and practice. Educ. Psychol. Rev., $18,315-341$.

Perry R. P. , Hladkyj S. , Pekrun R. H. , Pelletier S. T. (2001). Academic control and action control in the achievement of college students: a longitudinal field. J. Educ. Psychol. 93, 776-788.

Pintrich, P. R. (2000). The role of goal orientation in self-regulated learning Handbook of self-regulation (pp. 451-502): Elsevier.

Pintrich, P. R. (2004). A conceptual framework for assessing motivation and self-regulated learning in college students. Educational psychology review, 16(4), 385-407.

Ruthig, J. C., Haynes, T. L., Perry, R. P., \& Chipperfield, J.G. (2007). Academic optimistic bias: Implications for college student performance and well-being. Social Psychology of Education, 10(1), 115-137.

Segal, Z. V., Williams, J. M. G., \& Teasdale, J. D. (2002). Mindfulness based cognitive therapy for depression: A new approach to preventing relapse. New York: Guilford press

Solberg, N. L. \& Segerstrom, S. C. (2010). Dispositional optimism and coping: A metaanalytic review. J. Personal Soc Psychol Rev. (10), 235-51.

Shapiro, S. L., Carlson, L. E., Astin, J. A., \& Freedman, B. (2006). Mechanisms of mindfulness. Journal of clinical psychology, 62(3), 373-386.

Stupnisky, R. H., Perry, R. P., Renaud, R. D., \& Hladkyj, S. (2013). Looking beyond grades: Comparing self-esteem and perceived academic control as predictors of firstyear college students' well-being. Learning and Individual Differences, 23, 151-157. 
Thompson, S. C., Sobolew-Shubin, A., Galbraith, M. E., Schwankovsky, L., and Cruzen, D. (1993). Maintaining perceptions of control: Findings perceived control in low control circumstances. Journal of Personality and Social Psychology, 64, 293-304.

Viglas, M., \& Perlman, M. (2018). Effects of a mindfulness-based program on young children's self-regulation, prosocial behavior and hyperactivity. Journal of Child and Family Studies, 27 (4), 1150-1161.

You, J. W., \& Kang, M. (2014). The role of academic emotions in the relationship between perceived academic control and self-regulated learning in online learning. Computers \& Education, 77, 125-133.

Zimmerman, B. J. (1998). Academic studying and the development of personal skill: A self-regulatory perspective. Educational psychologist, 33(2-3), 73-86.

Zimmerman, B. J., \& Kitsantas, A. (2005). Homework practices and academic achievement: The mediating role of self-efficacy and perceived responsibility beliefs. Contemporary Educational Psychology, 30(4), 397-417. 